\title{
Glutamate Inhibits Thalamic Reticular Neurons
}

\author{
Charles L. Cox and S. Murray Sherman \\ Department of Neurobiology, State University of New York, Stony Brook, New York 11794-5230
}

\begin{abstract}
Activation of metabotropic glutamate receptors (mGluRs) can result in long-lasting modulation of neuronal excitability. Multiple mGluR subtypes are localized within the rat thalamic reticular nucleus (TRN), and we have examined the effects of activating these different receptor subtypes on the excitability of these neurons using an in vitro slice preparation. Typical of most mGluR-sensitive preparations, the general mGluR agonist, ( \pm )-1-aminocyclopentane-trans-1,3-dicarboxylic acid (ACPD) produced a robust, long-lasting excitatory response. Surprisingly, ACPD produced a membrane hyperpolarization in some neurons. Using selective mGluR agonists, we found that activation of group II mGluRs produces the hyperpolarization,
\end{abstract}

The thalamic reticular nucleus (TRN) consists of a thin layer of GABA-containing neurons that forms a shell predominantly lateral to the dorsal thalamus (Jones, 1985). All axons communicating between thalamus and cortex in both directions pass through and innervate the TRN. Because TRN neurons provide a powerful inhibitory input to thalamocortical relay cells, they are strategically situated to influence the responsiveness of thalamic relays (Cox et al., 1997; Kim et al., 1997; Sanchez-Vives et al., 1997). The activity of TRN neurons has been associated with various functions, including the regulation of receptive field sizes (Lee et al., 1994a,b) and the generation of synchronized oscillations among thalamic neurons during certain phases of sleep and forms of epilepsy (Steriade et al., 1986, 1993; Avoli et al., 1990; Buzsáki et al., 1990). Much of the afferent input to TRN derives from collaterals of both corticothalamic and thalamocortical axons, which are glutamatergic and thus have been widely assumed to be purely excitatory. Thus, most views of TRN are based on the idea that it provides a feedback inhibitory input to dorsal thalamus (i.e., being excited by glutamatergic relay cell axons and projecting back to these relay cells) and a feedforward inhibitory input from cortex (i.e., being excited by glutamatergic corticothalamic axons and projecting to thalamic relay cells).

Glutamate can activate multiple subtypes of both ionotropic and metabotropic receptors, primarily leading to EPSPs in the CNS. Activation of metabotropic glutamate receptors (mGluRs) is of increasing interest, because such activation through G-protein-coupled, second messenger pathways stereotypically produce long-lasting changes in neuronal excitability, in contrast to the relatively short-lasting actions of activating ionotropic glutamate receptors (iGluRs) (Watkins and Evans, 1981; Conn and Pin, 1997). At least eight subtypes of mGluRs have been

\footnotetext{
Received March 15, 1999; revised May 15, 1999; accepted May 20, 1999.

This research was supported by National Eye Institute Grant EY03038 from the National Institutes of Health.

Correspondence should be addressed to S. M. Sherman, Department of Neurobiology, State University of New York, Stony Brook, NY 11794-5230.

Copyright (C) 1999 Society for Neuroscience $0270-6474 / 99 / 196694-06 \$ 05.00 / 0$
}

whereas the depolarization is mediated by group I mGluRs. While the polarity of the postsynaptic response (hyperpolarization vs depolarization) was dependent on the mGluR subtype activated, both actions appear to result from modification of a linear $\mathrm{K}^{+}$conductance. The inhibitory action of Glutamate, via group II mGluRs, provides an avenue for a disinhibitory effect that could have interesting consequences upon a wellinvestigated, model neuronal circuit, turning its assumed functional role upside down.

Key words: thalamus; metabotropic glutamate receptors; thalamic reticular nucleus; inhibition; thalamocortical identified, and they are currently differentiated into three primary groups based on pharmacology, structural homology, and signal transduction mechanism (Nakanishi, 1992; Conn and Pin, 1997). Different mGluR subtypes have been associated with a variety of presynaptic and postsynaptic actions in many CNS regions (Watkins and Evans, 1981; Collingridge and Lester, 1989; Schoepp and Conn, 1993; Conn and Pin, 1997). Whereas activation of mGluRs usually results in a postsynaptic excitation (Charpak et al., 1990; Mercuri et al., 1993; Davies et al., 1995; Eaton and Salt, 1996; Lee and McCormick, 1997; Turner and Salt, 1998), several studies have indicated that $\mathrm{mGluR}$ activation may also produce a postsynaptic inhibitory response (Shirasaki et al., 1994; Holmes et al., 1996; Fiorillo and Williams, 1998). More specifically, activation of group II mGluRs produces a postsynaptic inhibitory response in basolateral amygdala (Holmes et al., 1996). This is of particular interest, because recent immunohistochemical evidence suggests that TRN cells possess several distinct types of mGluR (Ohishi et al., 1993a,b). The presence of group II mGluRs in particular suggest the possibility of glutamatergic inhibition of TRN cells, thereby dramatically changing our ideas of the functional circuitry involving TRN. We sought to test this possibility by pharmacological investigation of TRN cells in an in vitro thalamic slice preparation.

\section{MATERIALS AND METHODS}

Thalamic slices were prepared as previously described (Cox et al., 1998). Briefly, young Sprague Dawley rats (P10-P18) were deeply anesthetized with pentobarbital sodium $(50 \mathrm{mg} / \mathrm{kg})$, and the brains were quickly removed. Tissue slices $(300-350 \mu \mathrm{m})$ were cut in the horizontal plane using a vibratome in cold, oxygenated slicing medium containing (in $\mathrm{mm}$ ): $2.5 \mathrm{KCl}, 1.25 \mathrm{NaH}_{2} \mathrm{PO}_{4}, 10.0 \mathrm{MgCl}_{2}, 0.5 \mathrm{CaCl}_{2}, 26.0 \mathrm{NaHCO}_{3}$, 11.0, glucose and 234.0 sucrose. Slices were transferred to a holding chamber containing oxygenated $\left(5 \% \mathrm{CO}_{2}\right.$ and $\left.95 \% \mathrm{O}_{2}\right)$ physiological solution that contained (in $\mathrm{mM}$ ): $126.0 \mathrm{NaCl}, 2.5 \mathrm{KCl}, 1.25 \mathrm{NaH}_{2} \mathrm{PO}_{4}, 2.0$ $\mathrm{MgCl}_{2}, 2.0 \mathrm{CaCl}_{2}, 26.0 \mathrm{NaHCO}_{3}$, and 10.0 glucose for at least $1 \mathrm{hr}$ before recording. Individual slices were then transferred to a recording chamber maintained at $30 \pm 1^{\circ} \mathrm{C}$, and oxygenated physiological saline was continuously superfused at a rate of $3 \mathrm{ml} / \mathrm{min}$.

Whole-cell recordings were obtained from visually identified thalamic 
reticular neurons with differential interference contrast optics and infrared video microscopy. An Axoclamp2A amplifier (Axon Instruments, Foster City, CA) was used in bridge mode for voltage recordings and discontinuous single electrode voltage-clamp mode for current recordings. In voltage-clamp recordings, switching frequencies ranged from 3 to $4 \mathrm{kHz}$ with a gain of $300-800 \mathrm{pA} / \mathrm{mV}$, and the headstage was continually monitored to ensure that the current transient had completely decayed before voltage measurements. Voltage-clamp recordings were limited to neurons that had a stable access resistance of $<25 \mathrm{M} \Omega$. No correction for liquid junction potential has been made to the voltage measurements. Recording pipettes were pulled from $1.5 \mathrm{~mm}$ outer diameter capillary tubing and filled with the following intracellular solution (in $\mathrm{mM}$ ): $117 \mathrm{~K}$ gluconate, $13 \mathrm{KCl}, 1.0 \mathrm{MgCl}_{2}, 0.07 \mathrm{CaCl}_{2}, 0.1$ EGTA, 10.0 HEPES, 2.0 $\mathrm{Na}_{2}-\mathrm{ATP}$, and $0.4 \mathrm{Na}-\mathrm{GTP}$. In some experiments, Cs-gluconate and $\mathrm{CsCl}$ were substituted for $\mathrm{K}$-gluconate and $\mathrm{KCl}$, respectively, to suppress $\mathrm{K}^{+}$-mediated conductances. The $\mathrm{pH}$ of the solution was adjusted to 7.3 using $\mathrm{KOH}$ or $\mathrm{CsOH}$, and osmolality was adjusted to 280 mosm with distilled water.

Concentrated stock solutions of pharmacological agents were prepared in either distilled water or $0.1 \mathrm{M} \mathrm{NaOH}$ and diluted in physiological solution to final concentrations before use. Agonists were applied by injecting a bolus into the flow line of the chamber over 20-60 sec using a motorized syringe pump. Based on the rate of agonist injection and chamber perfusion, the final bath concentration of agonists were estimated to be approximately one-fourth of the concentration introduced in the flow line (Cox et al., 1995). Concentrations listed in the text are the concentrations of the injected agent before the fourfold dilution in the bath. Antagonists were diluted to a final concentration from concentrated stocks and bath-applied. All compounds were purchased from Tocris Cookson (St. Louis, MO) or Sigma (St. Louis, MO).

\section{RESULTS}

Current-clamp recordings of rat TRN neurons associated with the ventrobasal complex (the primary somatosensory thalamic relay) revealed that the general mGluR agonist ( \pm )-1aminocyclopentane-trans-1,3-dicarboxylic acid (ACPD; 125-250 $\mu \mathrm{M}$ ) produced a long-lasting robust depolarization (mean $\pm \mathrm{SD}$; $9.4 \pm 5.8 \mathrm{mV} ; n=11$ ) that could result in action potential discharge (Fig. 1A). The ACPD-mediated depolarization was associated with an increase in input resistance and persisted in the presence of tetrodotoxin (TTX; $1 \mu \mathrm{M}$ ), suggesting that activation of postsynaptic mGluRs on the recorded cell underlies the alteration in membrane potential (Fig. 1A). Given that ACPD is a general agonist for both group I and II mGluR subtypes, specific mGluR agonists were then tested on TRN neurons. The selective group I agonist $(R S)$-3,5-dihroxyphenylglycine (DHPG; $250-500 \mu \mathrm{M})$ with and without TTX $(1 \mu \mathrm{M})$ also produced a strong depolarization with an increased input resistance similar to that seen with ACPD (Fig. 1B). At these concentrations (250-500 $\mu \mathrm{M})$, suprathreshold depolarizations were commonly observed.

In contrast, the selective group II agonist $S$-3-carboxy-4hydroxyphenylglycine (S3-C4HPG; 500-2000 $\mu \mathrm{M}$ ) produced a small amplitude membrane hyperpolarization in TRN cells (Fig. $1 C$ ). This hyperpolarization was observed in 18 of 26 neurons and had an average peak amplitude of $1.5 \pm 0.6 \mathrm{mV}$ (range, 0.9-3.2 $\mathrm{mV})$. It also persisted in TTX $(1 \mu \mathrm{M})$, suggesting a postsynaptic action (Fig. 1C). We also saw some evidence for a slight decrease in input resistance during these current-clamp recordings, but the changes were small, variable, and often unreliable. We thus chose the more sensitive technique of measuring current responses to ramped command voltages during voltage-clamp recording to obtain a more reliable measure of changed input resistance, and this is described below.

Further support of this hyperpolarizing action of group II mGluR activation was provided by a different agent, $\left(2 S, 1^{\prime} R\right.$, $\left.2^{\prime} R, 3^{\prime} R\right)$-2-(2',3'-dicarboxycyclopropyl)-glycine (DCG IV), a po-
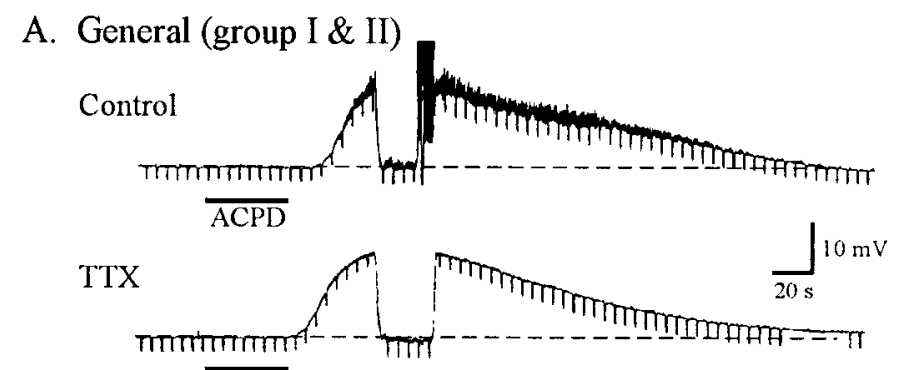

\section{B. Group I}

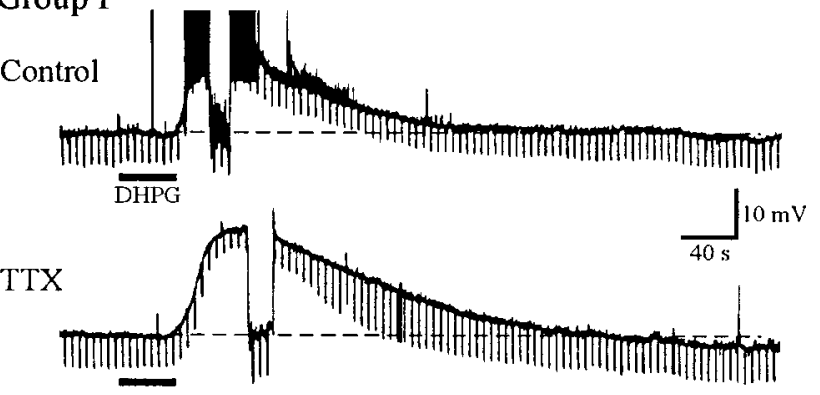

C. Group II

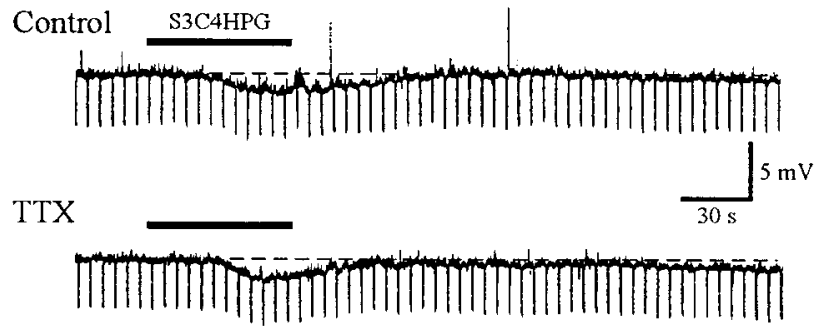

Figure 1. Activation of mGluRs alters excitability of a TRN neuron. These examples reflect current-clamp recording. A, Control, ACPD (125 $\mu \mathrm{M}$, thick line under recording) produces a long-lasting membrane depolarization leading to spike discharge (spikes truncated). The depolarization is interrupted for $20-30 \mathrm{sec}$ by current injection to repolarize the membrane to the pre-ACPD level $(-70 \mathrm{mV})$, thereby controlling for any voltage-dependent effects while comparing pre-ACPD and post-ACPD input resistance. During the depolarization, there is an increase in baseline activity, presumably representing EPSPs originating from suprathreshold excitation by the ACPD of afferent glutamatergic inputs (e.g., from ventrobasal relay cells that are generally connected the TRN neurons in these slice preparation). $A, T T X$, With addition of TTX $(1 \mu \mathrm{M})$, the ACPD-mediated depolarization persists, but the increase in baseline activity is eliminated as are, of course, the action potentials. In both Control and TTX, the increased amplitude of membrane responses to the hyperpolarizing current steps indicate an increase in neuronal input resistance. $B$, Control, In a different TRN neuron, the group I mGluR agonist DHPG $(250 \mu \mathrm{M})$ produces a robust depolarization, evoking action potentials (spikes truncated) as well as a robust increase in baseline activity. $B, T T X$, The DHPG depolarization persists in the presence of TTX $(1 \mu \mathrm{M})$. As in $A$, the larger voltage responses to hyperpolarizing current steps after the membrane potential is manually returned to the pre-DHPG level of $-74 \mathrm{mV}$ indicate a decrease in input resistance. $C$, Control, The selective group II mGluR agonist S3-C4HPG $(500 \mu \mathrm{M})$ produces a small membrane hyperpolarization from the initial membrane potential of $-65 \mathrm{mV}$ (the dashed line serves as a reference to this), and the responses to current steps indicate a small decrease in neuronal input resistance in a different TRN neuron. $C, T T X$, The S3-C4HPG-mediated hyperpolarization persists in TTX $(1 \mu \mathrm{M})$.

tent agonist of group II mGluRs that also activates NMDA receptors. Similar to S3-C4HPG, DCG IV $(100 \mu \mathrm{M})$ produced an initial hyperpolarization, followed by a robust, AP-5-sensitive depolarization as predicted by the mixed action of this agonist on both group II mGluRs and NMDA receptors ( $n=4$; data not shown). 


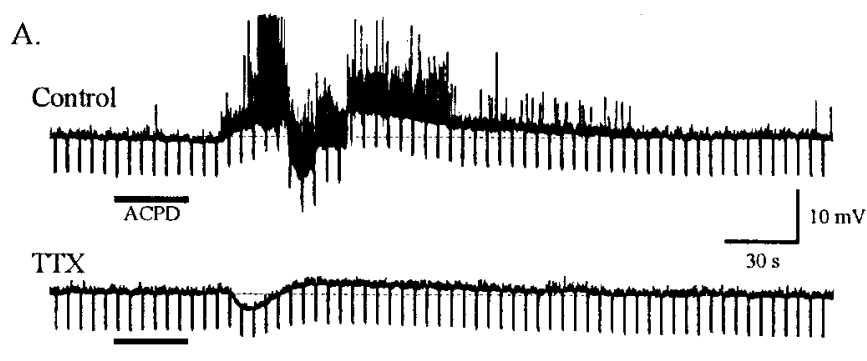

B.

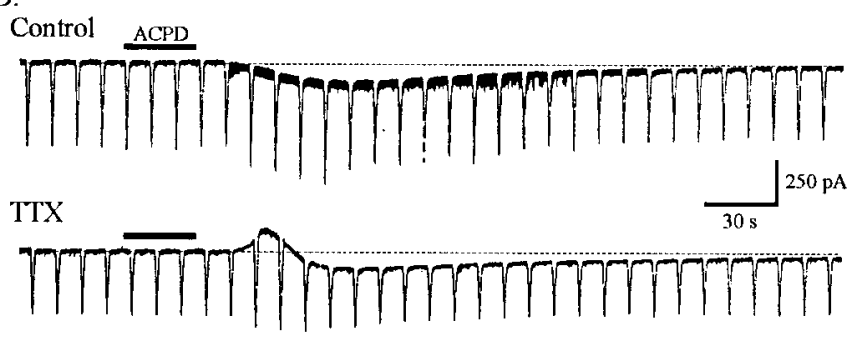

Figure 2. Biphasic actions of ACPD on TRN cells. A, Control, In control conditions during current-clamp recording, ACPD $(125 \mu \mathrm{M})$ produces a depolarization associated with a large increase in spontaneous depolarizations (presumed EPSPs), and action potentials are evoked. The depolarization is interrupted by a manual return of the membrane voltage to the pre-ACPD level of $-63 \mathrm{mV}$. A, TTX, With the addition of TTX (1 $\mu \mathrm{M})$, ACPD produces an early hyperpolarization with reduced input resistance followed by a longer lasting depolarization with increased input resistance. $B$, Control, In a voltage-clamp recording from a different neuron, ACPD $(125 \mu \mathrm{M})$ produces an inward current associated with an increase in small inward currents, which are presumed EPSCs. $B, T T X$, With the addition of TTX $(1 \mu \mathrm{M})$, ACPD no longer produces an increase in baseline activity but does evoke an initial outward current followed by a longer-lasting inward current. See legend to Figure 3 for explanation of the downward deflections during the voltage-clamp recording.

In three neurons, ACPD produced an apparent biphasic action. That is, in control conditions ACPD produced the typical membrane depolarization associated with an increased baseline activity (Fig. 2A). However, in TTX (1 $\mu \mathrm{M})$, ACPD produced an initial relatively brief hyperpolarization that was followed by a longer lasting depolarization (Fig. $2 A, T T X$ ). Similarly, voltageclamp recordings from a different neuron indicate that, in control conditions, ACPD produced a net inward current as expected by group I mGluR activation (Fig. 2B). When TTX (1 $\mu \mathrm{M})$ was added to the preparation for this neuron, ACPD produced a short-lasting outward current that was followed by a longer lasting inward current (Fig. 2B, TTX). Furthermore, during the initial outward current there is an increase in the current response to the ramped voltage commands (Fig. 2B, downward deflections) indicative of an increased conductance, and the opposite is observed during the inward current (decreased membrane response). These data indicate that both the group I and II mGluRmediated responses can occur in the same TRN neurons, and furthermore they can be elicited by the general mGluR agonist.

To further investigate the mechanisms underlying the mGluRmediated membrane potential changes, voltage-clamp recordings using ramped voltage commands $(-50$ to $-90 \mathrm{mV})$ were used to quantify alterations in input conductance. In control conditions, ACPD produced a net inward current that had an average peak of $67.0 \pm 32.0 \mathrm{pA}(n=10)$ that persisted in $1 \mu \mathrm{M}$ TTX (Fig. $3 A i)$. During the ACPD-induced inward current, the slope of the current response to the ramped voltage commands was signifi- cantly decreased, reflecting a reduction in input conductance $(p<0.05$; paired Student's $t$ test; $n=6$; Fig. 3Aii). This decreased conductance averaged $0.69 \pm 0.55 \mathrm{nS}$ (range, 0.06-1.49 $\mathrm{nS}$ ), accounting for a $1-15 \%$ reduction in resting conductance. The ACPD-altered current appears linear over the tested voltage range $(-50$ to $-90 \mathrm{mV})$ and reversed near $E_{\mathrm{K}}$, indicating that ACPD likely decreases a $\mathrm{K}_{\text {leak }}$ conductance (Fig. 3Aiii). Similarly, the group I agonist DHPG also produced a TTX-insensitive inward current (Fig. 3Bi) associated with a significant reduction of a conductance that reverses near $E_{\mathrm{K}}$ (Fig. 3 Bii, iii; $p<0.05 ; n=5$ ).

In contrast, the selective group II mGluR agonist S3-C4HPG produced a TTX-insensitive outward current (Fig. 3Ci; $20.2 \pm$ $17.0 \mathrm{pA} ; n=13$; range, 7-73 pA). The S3-C4HPG outward current was associated with a significant increase in resting membrane conductance ( $p<0.05 ; n=10$; Fig. 3Cii). This increased conductance averaged $0.48 \pm 0.49 \mathrm{nS}$ (range, 0.07-1.74 nS) accounting for a 1-18\% increase in resting conductance. This current appears linear and also reverses near $E_{\mathrm{K}}$, suggesting group II mGluR activation increases a $\mathrm{K}_{\text {leak }}$ conductance (Fig. 3Ciii). Thus, although our data are consistent with the possibility that activation of group I or II mGluRs alters an apparent, single linear $\mathrm{K}^{+}$conductance, we do not have the data necessary to determine whether this is a single conductance involving one group of $\mathrm{K}^{+}$channels or multiple conductances and $\mathrm{K}^{+}$channel types. Nonetheless, our experiments indicate that the direction of the conductance change (increase or decrease) is dependent on the mGluR subtype activated.

The role of mGluRs mediating this hyperpolarization was further supported by the reversible antagonism of the S3C4HPG-mediated hyperpolarization by the general mGluR antagonist $(R S)$ - $\alpha$-methyl-4-carboxyphenylglycine (MCPG), as illustrated in Figure $4 A(n=3)$. In addition, because the voltageclamp recordings suggest that activation of either group I or II mGluRs alters $\mathrm{K}^{+}$conductances, $\mathrm{Cs}^{+}$-containing recording pipettes were used to suppress $\mathrm{K}^{+}$currents. As Figure $4 B$ illustrates, the ACPD-mediated inward current was absent or very small in these recording conditions $(n=6)$. Furthermore, the S3-C4HPG-induced outward current was also absent $(n=3)$.

\section{DISCUSSION}

Our results thus indicate that glutamate can produce postsynaptic inhibitory responses in TRN cells in addition to the typical excitatory action that has been described in many preparations. This inhibition occurs through activation of group II mGluRs, which hyperpolarizes TRN neurons by increasing a linear $\mathrm{K}^{+}$ conductance, whereas activation of group I mGluRs suppresses a $\mathrm{K}^{+}$conductance resulting in a membrane depolarization. Although the predominant action of the general agonist ACPD is a depolarization, a biphasic action of mGluR activation can occur within some TRN neurons, suggesting the presence of both receptor subtypes on these cells. Furthermore, although all TRN neurons tested produced the group I mGluR mediated depolarization, approximately two-thirds also exhibited the group IImediated hyperpolarization. This difference suggests that group II mGluRs are differentially distributed on TRN neurons or perhaps that all TRN cells possess group II mGluR activity, but that for some, the level of activity is insufficient to be detected by our somatic recordings.

In any case, our findings indicate that activation of glutamatergic inputs to many TRN cells from thalamocortical and/or corticothalamic axons can provide both excitatory and inhibitory 
A ACPD
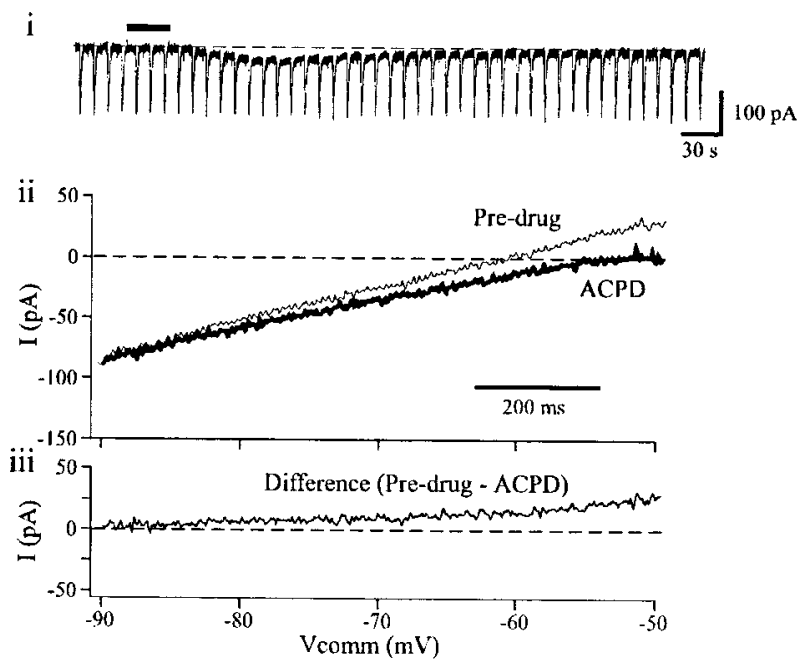

B DHPG

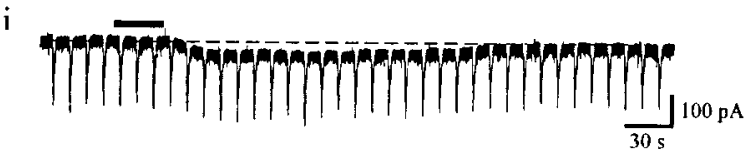

ii
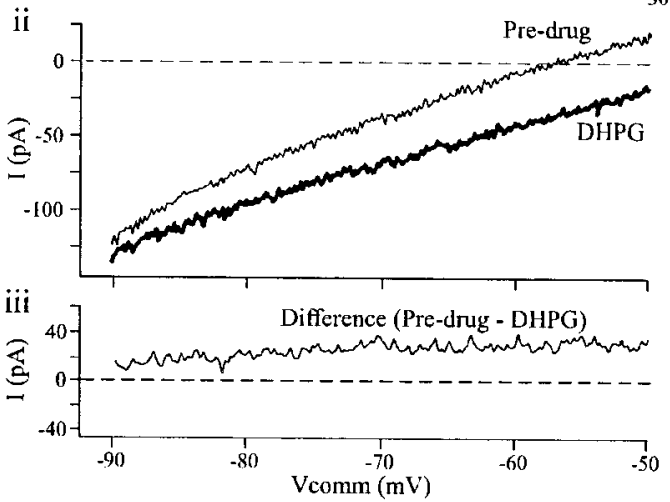

C S3C4HPG

i
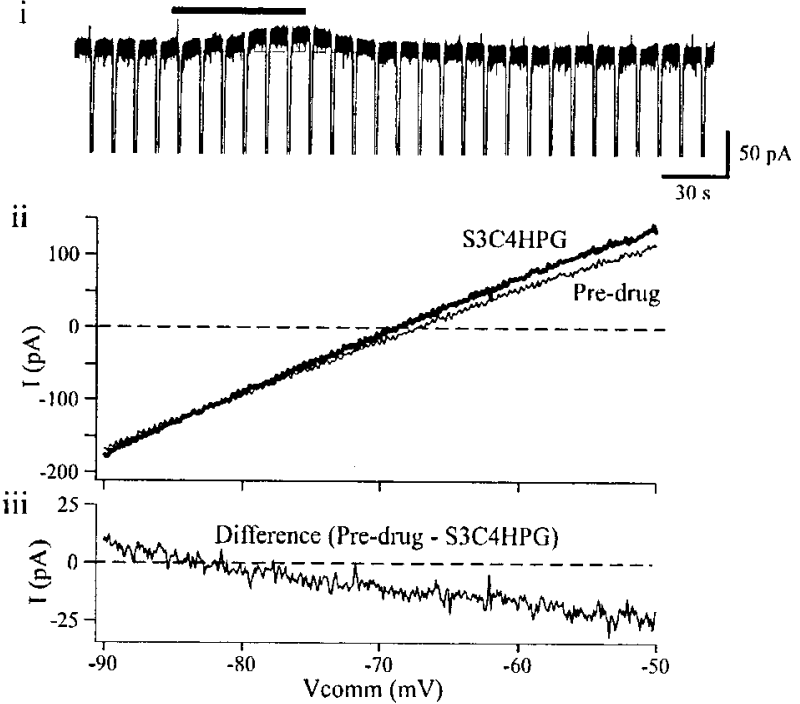

Figure 3. Activation of different mGluR subtypes during voltage-clamp recording in the presence of TTX $(1 \mu \mathrm{M})$ differentially alters $\mathrm{K}^{+}$conductances. $A i$, The general mGluR agonist ACPD $(125 \mu \mathrm{M})$ produces an influences depending on the specific glutamate receptors activated. Of obvious importance is whether endogenous activation of these different mGluR subtypes is specific to particular glutamatergic afferents, such as a subset of corticothalamic and/or thalamocortical axons. A precedent for such specificity exists in thalamus for glutamatergic inputs. For example, activation of group I mGluRs on relay neurons, which produces long-lasting EPSPs, appears specific to the corticothalamic pathway and not the retinogeniculate, both of which are glutamatergic (McCormick and von Krosigk, 1992; Godwin et al., 1996).

Thus, the overall, sustained influence of activating these two mGluR subtypes (groups I and/or II) by synaptically released glutamate on the excitability of TRN neurons remains unknown. We assume that iGluRs activated by these glutamatergic inputs provide relatively fast EPSPs, and given evidence elsewhere that mGluR activation requires higher afferent activity than does activation of iGluRs (McCormick and von Krosigk, 1992), there could be an interesting frequency-dependent effect in which certain corticothalamic or thalamocortical inputs to TRN cells begin to inhibit these cells only when relatively active. Also, the more sustained effects of mGluR activation would last well beyond iGluR activation. We suggest three different possibilities that require further investigation. First, individual glutamatergic afferents can activate both group I and II mGluRs, leading to a predominant excitatory response that negates small hyperpolarizing actions. Second, individual glutamatergic afferents may activate only group I or II mGluRs. If those activating group II mGluRs do not activate iGluRs, the postsynaptic effect would be pure inhibition, and even if they did activate both receptor types the mGluR-mediated inhibition would outlast the iGluRmediated excitation. Third, a given axon may synapse on both group I and II mGluRs, but activation of these different subtypes may be differentially frequency-dependent, with one effect dominating at lower levels of afferent activity, and the other, at higher levels.

Although the functional significance of endogenous glutamate release on mGluRs remains unanswered, our data suggest several hypotheses that need further investigation. Clearly, TRN cells

$\leftarrow$

inward current associated with a decrease in amplitude of the downward deflections. These deflections are current responses to ramped voltage commands ( -50 to $-90 \mathrm{mV}, 2 \mathrm{sec}$ duration). Thus, the reduced amplitude of the deflections reflects an increase in input resistance. Aii, Expanded traces of the averaged recorded current responses $(I ; n=5)$ versus the ramped voltage commands before (Pre-drug, thin line) and during ( $A C P D$, thick line) the peak ACPD response. In response to ACPD, there is an inward shift of the holding current (indicative of the inward current) and decreased slope of the membrane response, indicating a decreased conductance. Aiii, Difference between the pre-drug and ACPD traces in Aii, thereby showing the ACPD-mediated current response. The extrapolated reversal potential of this current is $-90 \mathrm{mV}$. Bi, From a different TRN neuron, the specific group I mGluR agonist DHPG $(250 \mu \mathrm{M})$ produces an inward current similar to that seen in $A i$ with ACPD. Bii, Average of five responses as in Aiii to the ramped voltage commands before (Pre-drug) and during $(D H P G)$ the peak agonist response. DHPG produces a decreased slope of the current response, as in Aii. Biii, The extrapolated reversal potential of the DHPG-mediated current was $-94 \mathrm{mV}$. Ci, From the TRN neuron in Figure $1 C$, the selective group II mGluR agonist S3-C4HPG $(500 \mu \mathrm{M})$ produces a small outward current. The downward deflections that are membrane responses to voltage ramps are truncated in this illustration. Cii, Average of five responses as in Aiii to the ramped voltage commands before (Pre-drug) during (S3-C4HPG) the peak agonist response. Note the increased slope of the response to S3-C4HPG. Ciii, The extrapolated reversal potential of the increased current was $-85 \mathrm{mV}$. 
A.
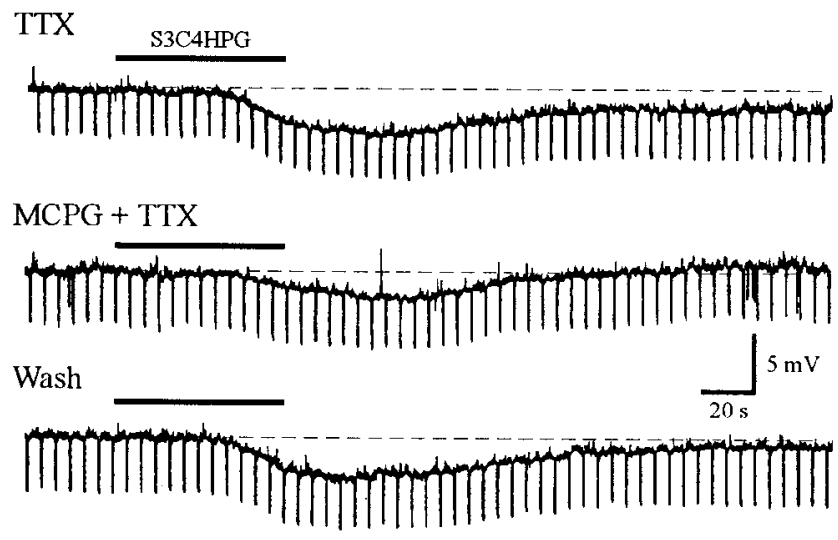

B.

Control
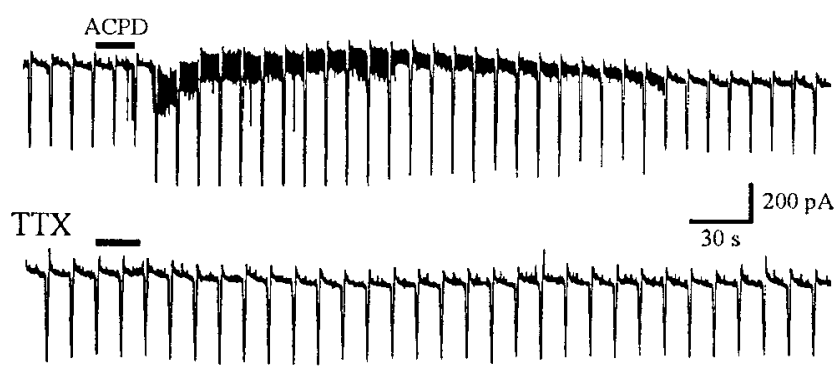

C.

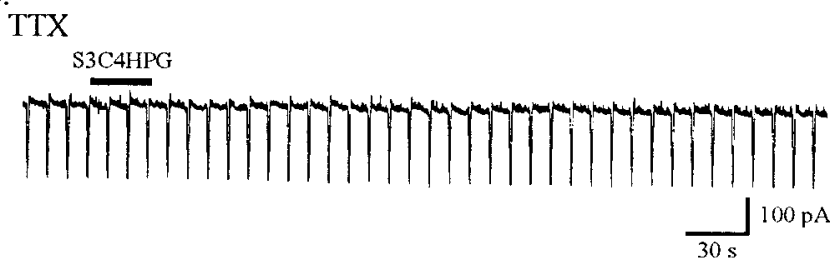

Figure 4. A, Current-clamp recording showing attenuation by mGluR antagonists of group II mGluR agonist-mediated hyperpolarization of TRN cell. $A, T T X$, In TTX $(1 \mu \mathrm{M})$, the group II agonist S3-C4HPG (500 $\mu \mathrm{M})$ produces a membrane hyperpolarization. $A, M C P G+T T X$, The S3-C4HPG hyperpolarization is partially attenuated by the presence of the general mGluR antagonist MCPG $(500 \mu \mathrm{M})$. A, Wash, After a $23 \mathrm{~min}$ wash in TTX-containing solution, the S3-C4HPG-mediated hyperpolarization recovers. Initial $\mathrm{Vm}=-59 \mathrm{mV} . B$, Voltage-clamp recording in another TRN cell showing that the mGluR-mediated effects are suppressed by $\mathrm{Cs}^{+}$in the electrode. $B$, Control, In control conditions, ACPD produces a robust alteration in baseline activity, presumably increasing spontaneous EPSCs via suprathreshold activation of synaptically connected relay neurons. $B, T T X$, In the presence of TTX $(1 \mu \mathrm{M})$, ACPD does not alter the holding current or spontaneous baseline activity. $C, T T X$, During voltage-clamp recording from a different TRN neuron in TTX $(1 \mu \mathrm{M})$, the selective group II mGluR agonist S3-C4HPG produces no obvious change in resting current levels or responses to voltage ramps.

powerfully inhibit thalamic relay cells, thereby providing an important control of thalamic relay functions (Cox et al., 1997; Kim et al., 1997). As noted above, all previous ideas of TRN functioning were based on the belief that corticothalamic and thalamocortical axon collaterals, which form a major input to TRN neurons, strictly excite these cells. The fact of group II-mediated inhibition of TRN cells raises the possibility that specific inputs from cortex or dorsal thalamus can inhibit TRN cells. (In this sense, "specific" refers to certain afferents and/or certain patterns of afferent activity.) Our data thus indicate that significant inhibition may also result from corticothalamic and/or thalamocortical inputs to TRN cells. If so, then ideas of TRN functioning and control by these glutamatergic afferents are more complex and richer than previously thought.

\section{REFERENCES}

Avoli M, Gloor P, Kostopoulos G (1990) Thalamocortical relationships in generalized epilepsy with bilaterally synchronous spike-and-wave discharge. In: Generalized epilepsy: neurobiological approaches (Avoli M, Gloor P, Kostopoulos G, Naquet R, eds), pp 190-212. Boston: Birkhauser.

Buzsáki G, Smith A, Berger S, Fisher LJ, Gage FH (1990) Petit mal epilepsy and parkinsonian tremor: hypothesis of a common pacemaker. Neuroscience 36:1-14.

Charpak S, Gähwiler BH, Do K-Q, Knöpfel T (1990) Potassium conductances in hippocampal neurons blocked by excitatory amino-acid transmitters. Nature 347:765-767.

Collingridge GL, Lester RA (1989) Excitatory amino acid receptors in the vertebrate central nervous system. Pharmacol Rev 40:143-210.

Conn PJ, Pin JP (1997) Pharmacology and functions of metabotropic glutamate receptors. Annu Rev Pharmacol Toxicol 37:205-237.

Cox CL, Huguenard JR, Prince DA (1995) Cholecystokinin depolarizes rat thalamic reticular neurons by suppressing a $\mathrm{K}^{+}$conductance. J Neurophysiol 74:990-1000.

Cox CL, Huguenard JR, Prince DA (1997) Nucleus reticularis neurons mediate diverse inhibitory effects in thalamus. Proc Natl Acad Sci USA 94:8854-8859.

Cox CL, Zhou Q, Sherman SM (1998) Glutamate locally activates dendritic outputs of thalamic interneurons. Nature 394:478-482.

Davies CH, Clarke VR, Jane DE, Collingridge GL (1995) Pharmacology of postsynaptic metabotropic glutamate receptors in rat hippocampal CA1 pyramidal neurones. Br J Pharmacol 116:1859-1869.

Eaton SA, Salt TE (1996) Role of $N$-methyl-D-aspartate and metabotropic glutamate receptors in corticothalamic excitatory postsynaptic potentials in vivo. Neuroscience 73:1-5.

Fiorillo CD, Williams JT (1998) Glutamate mediates an inhibitory postsynaptic potential in dopamine neurons. Nature 394:78-82.

Godwin DW, Van Horn SC, Erisir A, Sesma M, Romano C, Sherman SM (1996) Ultrastructural localization suggests that retinal and cortical inputs access different metabotropic glutamate receptors in the lateral geniculate nucleus. J Neurosci 16:8181-8192.

Holmes KH, Keele NB, Arvanov VL, Shinnick-Gallagher P (1996) Metabotropic glutamate receptor agonist-induced hyperpolarizations in rat basolateral amygdala neurons: receptor characterization and ion channels. J Neurophysiol 76:3059-3069.

Jones EG (1985) The thalamus. New York: Plenum.

Kim U, Sanchez-Vives MV, McCormick DA (1997) Functional dynamics of GABAergic inhibition in the thalamus. Science 278:130-134.

Lee KH, McCormick DA (1997) Modulation of spindle oscillations by acetylcholine, cholecystokinin and $1 S, 3 R$-ACPD in the ferret lateral geniculate and perigeniculate nuclei in vitro. Neuroscience 77:335-350.

Lee SM, Friedberg MH, Ebner FF (1994a) The role of GABA-mediated inhibition in the rat ventral posterior medial thalamus. I. Assessment of receptive field changes following thalamic reticular nucleus lesions. J Neurophysiol 71:1702-1715.

Lee SM, Friedberg MH, Ebner FF (1994b) The role of GABA-mediated inhibition in the rat ventral posterior medial thalamus. II. Differential effects of GABAA and GABAB receptor antagonists on responses of VPM neurons. J Neurophysiol 71:1716-1726.

McCormick DA, von Krosigk M (1992) Corticothalamic activation modulates thalamic firing through glutamate "metabotropic" receptors. Proc Natl Acad Sci USA 89:2774-2778.

Mercuri NB, Stratta F, Calabresi P, Bonci A, Bernardi G (1993) Activation of metabotropic glutamate receptors induces an inward current in rat dopamine mesencephalic neurons. Neuroscience 56:399-407.

Nakanishi S (1992) Molecular diversity of glutamate receptors and implications for brain function. Science 258:597-603. 
Ohishi H, Shigemoto R, Nakanishi S, Mizuno N (1993a) Distribution of the messenger RNA for a metabotropic glutamate receptor, mGluR2, in the central nervous system of the rat. Neuroscience 53:1009-1018.

Ohishi H, Shigemoto R, Nakanishi S, Mizuno N (1993b) Distribution of the mRNA for a metabotropic glutamate receptor (mGluR3) in the rat brain: an in situ hybridization study. J Comp Neurol 335:252-266.

Sanchez-Vives MV, Bal T, McCormick DA (1997) Inhibitory interactions between perigeniculate GABAergic neurons. J Neurosci 17:8894-8908.

Schoepp DD, Conn PJ (1993) Metabotropic glutamate receptors in brain function and pathology. Trends Neurosci 14:13-20.

Shirasaki T, Harata N, Akaike A (1994) Metabotropic glutamate re- sponse in acutely dissociated hippocampal CA1 pyramidal neurones of the rat. J Physiol (Lond) 475:439-453.

Steriade M, Domich L, Oakson G (1986) Reticularis thalami neurons revisited: activity changes during shifts in states of vigilance. J Neurosci 6:68-81.

Steriade M, McCormick DA, Sejnowski TJ (1993) Thalamocortical oscillations in the sleeping and aroused brain. Science 262:679-685.

Turner JP, Salt TE (1998) Characterization of sensory and corticothalamic excitatory inputs to rat thalamocortical neurones in vitro. J Physiol (Lond) 510:829-843.

Watkins JC, Evans RH (1981) Excitatory amino acid transmitters. Annu Rev Pharmacol Toxicol 21:165-204. 